\title{
Functional Characterization of CRISPR-Cas System in the Ethanologenic Bacterium Zymomonas mobilis ZM4
}

\author{
Ge Dong1, Mingxiong He², Hong Feng ${ }^{*}$ \\ ${ }^{1}$ Sichuan Key Laboratory of Molecular Biology and Biotechnology, The Key Laboratory for Bio-Resources and \\ Eco-Environment of the Ministry of Education, College of Life Sciences, Sichuan University, Chengdu, China \\ ${ }^{2}$ Biomass Energy Technology Research Center, Biogas Institute of Ministry of Agriculture, Chengdu, China \\ Email: *hfeng@scu.edu.cn
}

Received 29 January 2016; accepted 12 March 2016; published 15 March 2016

Copyright (C) 2016 by authors and Scientific Research Publishing Inc.

This work is licensed under the Creative Commons Attribution International License (CC BY).

http://creativecommons.org/licenses/by/4.0/

(c) (i) Open Access

\begin{abstract}
CRISPR-Cas (clustered regularly interspaced short palindromic repeats-CRISPR associated proteins) is a RNA-guided defense immune system that prevents some genetic elements such as plasmids and virus from getting into the bacterial cells. Zymomonas mobilis is an ethanologenic bacterium, which encodes a subtype I-F CRISPR-Cas system containing three CRISPR loci and a far distant cas gene cluster. Reverse transcription (RT)-PCR analysis revealed that the CRISPR loci were transcribed on both strands. The Cas proteins were suggested to be expressed based on the previous transcriptomic analysis. Challenging with the invader plasmids containing the artificial protospacer with the protospacer adjacent motif (PAM) of NGG or GG exhibited immune interference activity. However, PAM motif of GG seems more effective than NGG in interference activity. Further, the artificial CRISPR arrays with the spacer sequences targeting to the specific genome sites could also lead to strong immune activity, resulting in almost no transformant grown on the agar plates. It was suggested that bacteria like $Z$. mobilis ZM4 are lack of the rejoining function to heal the double breakage of genomic DNA made by the CRISPR system. Conclusively, the Type I-F CRISPRCas system in Z. mobilis ZM4 is active to functionally defense the invading DNA elements.
\end{abstract}

\section{Keywords}

Zymomonas mobilis, CRISPR-Cas, Transcription, Immune, Interference

\section{Introduction}

CRISPR-Cas systems (clustered regularly interspaced short palindromic repeats-CRISPR-associated proteins) "Corresponding author.

How to cite this paper: Dong, G., He, M.X. and Feng, H. (2016) Functional Characterization of CRISPR-Cas System in the Ethanologenic Bacterium Zymomonas mobilis ZM4. Advances in Microbiology, 6, 178-189.

http://dx.doi.org/10.4236/aim.2016.63018 
occur widely in bacteria and Archaea [1]. The CRISPR array is consisted of the identical short repeat sequences and the unique spacers that are inserted between two repetitive sequences. And a cluster of protein-encoding genes named as CRISPR-associated (cas) gene is usually near by the CRISPR array. Based on the Cas protein sequences, CRISPR-Cas systems are classified into three major types and several subtypes [2] [3].

Currently, CRISPR-Cas system has been proved as an adaptive immune mechanism against mobile DNA elements like viruses and plasmids [4]. This RNA-guided adaptive immune mechanism mainly involves three phases, adaption, expression and interference. In the first stage, a piece of invader DNA is integrated into the 5 '-end of the CRISPR loci as a new spacer. Recently, the integration mechanism is reported for acquirement of new spacer [5] [6]. In the expression stage, a long primary CRISPR RNA (pre-crRNA) is transcribed from the CRISPR locus driven by the leader sequence, which is then processed by Cas proteins to generate mature crRNA species [7]. In the last phase, the Cas proteins and crRNA form a ribonucleoprotein complex which is response to recognize the target invader nucleic acid by a complementary manual and hence degrade the target DNA [8] [9]. In the Type II, a single protein Cas9, as well as the corresponding guide RNA is developed as a powerful technique in genomic editing both in prokaryotic and eukaryotic cells [10] [11].

During the adaptation and interference stages, recognition of the protospacer and target nucleic acid by the CRISPR systems absolutely requires a short sequence motif named as the nearby protospacer adjacent motif (PAM). PAM sequence requirement varies between CRISPR-Cas types [12]. In general, multiple PAMs could be effective both in adaptation and interference for the same CRISPR-Cas system. For example, six different PAMs identified to be required to permit target DNA recognition [13]. However, the requirement of PAM seems more flexible in recognition of spacer acquirement than in the interference [14].

Nowadays, functional studies of CRISPR-Cas systems have been widely applied to various bacteria. And some evidences indicate that not all CRISPR-Cas systems are capable to conferring the immune interference to foreign DNA elements [7] [15]. Zymomonas mobilis is a Gram-negative bacterium and is regarded as a potential fuel ethanol producer due to the characteristic of ethanol fermentation metabolic pathways [16]. Compared with the yeast, Z. mobilis ZM4 produces less cells, higher ethanol tolerance and ethanol production rate. Further, various strains of $Z$. mobilis also encode CRISPR-Cas systems in their genome and plasmid (Table S1) [17][22]. In this work, functional characterization of the CRISPR-Cas system was performed using the Z. mobilis ZM4 strain. We figured out that the transcription of the CRISPR locus occurred on both strands, but differentially. And the CRISPR-Cas system is active to defense against the invader plasmid DNA via cognate crRNAs derived from the transcripts.

\section{Materials and Methods}

\subsection{Strains, Plasmids and Growth Conditions}

The bacterial strains and plasmids used in this work were listed in Table S2. Z. mobilis ZM4 was routinely grown at $30^{\circ} \mathrm{C}$ in RM broth $\left(20.0 \mathrm{~g} / \mathrm{L}\right.$ glucose, $10.0 \mathrm{~g} / \mathrm{L}$ yeast extract, $1.0 \mathrm{~g} / \mathrm{L} \mathrm{MgSO}_{4}, 1.0 \mathrm{~g} / \mathrm{L}\left(\mathrm{NH}_{4}\right)_{2} \mathrm{SO}_{4}, 2.0$ $\mathrm{g} / \mathrm{L} \mathrm{KH}_{2} \mathrm{PO}_{4}$ ) or RM agar plate. If needed, kanamycin was added in the $\mathrm{RM}$ medium at $200 \mu \mathrm{g} / \mathrm{mL}$. The cultures of Escherichia coli DH5 $\alpha$ were grown in Luria-Bertani (LB) broth (1\% peptone, $0.5 \%$ yeast, $0.5 \% \mathrm{NaCl}$ ) at $37^{\circ} \mathrm{C}$ or with addition of antibiotics if needed.

\subsection{Maintaining the Integrity of the Specifications}

The total RNAs were isolated from $6 \mathrm{~mL}$ culture of Z. mobilis ZM4 growing in RM for $12 \mathrm{~h}$ and $16 \mathrm{~h}$ under stationary condition by using the Bacterial RNA Kit (Omega Biotech Co, Atlanta, USA) according to the manufacturer's instructions. Then PrimeScript ${ }^{\mathrm{TM}}$ RT reagent Kit with g DNA Eraser (Takara Biotech Inc., Dalian, China) was used to perform the reverse transcriptional reaction using $1.0 \mu \mathrm{g}$ total RNA prior to removal of the genomic DNA and the specific primers of ZmC1S3.F, ZmC1S6.R, ZmC2S2.F, ZmC2S5.R (Table S3), respectively. The resulting cDNAs were used to detect the target transcripts of CRISPR loci P1 and P2 by PCR with the specific primer pairs (ZmC1S3.F/ZmC1S6.R, ZmC2S2.F/ZmC2S5). The PCR cycles were initiated at $94^{\circ} \mathrm{C}$ for 4 min to denature the template DNA, followed by 25 or 32 amplification cycles. Each amplification cycle consisted of $94^{\circ} \mathrm{C}$ for $30 \mathrm{sec}, 55^{\circ} \mathrm{C}$ for $30 \mathrm{sec}$ and $72^{\circ} \mathrm{C}$ for $30 \mathrm{sec}$. And then, the PCR products were analysis on $2 \%$ agarose gel. In addition, the same primer pairs were used to amplify the RNA samples to examine if the RNA samples was contaminated with the genomic DNA or not. 


\subsection{Construction of the Invader Plasmids}

The invasion plasmid was constructed by the PCR using pBBR1MCS2 [23] as template and the overlapped primers (Table S3), which contained the spacer 1 and 3 of the CRISPR locus P1 of Z. mobilis ZM4. In addition, TGG or GG were introduced at 3'-end of the spacer sequence to serve as protospacer, respectively, since TGG or GG was demonstrated as an effective PAM site in the another type I-F of CRISPR-Cas systems [24]-[26]. PCR amplification with the KOD Plus DNA polymerase (Toyobo Co., Ozaka, Japan) following cycling steps: pre-denaturation $94^{\circ} \mathrm{C}$ for $4 \mathrm{~min}$; denaturation $94^{\circ} \mathrm{C}$ for $30 \mathrm{sec}$, annealing at $52^{\circ} \mathrm{C}-54^{\circ} \mathrm{C}$ (for various primer pair) for $30 \mathrm{sec}$, extension $68^{\circ} \mathrm{C}$ for $6 \mathrm{~min}, 30$ cycles; and final extension at $68^{\circ} \mathrm{C}$ for $10 \mathrm{~min}$. The PCR product, after digested by DpnI (Thermo scientific, Massachusetts, USA) was transformed into E. coli DH5 $\alpha$ competent cells. The inserted spacer sequence and PAM site were confirmed by DNA sequencing.

\subsection{Electriporation Transformation}

Transformation of Z. mobilis ZM4 was following the previous description [27] with minor modification. In brief, the cells were cultured in RM broth to the middle log-growth phase at $30^{\circ} \mathrm{C}$ in stationary condition. The cells were collected and washed with ice-cold $\mathrm{dd}_{\mathrm{H}} \mathrm{O}$ containing $10 \%$ glycerol by centrifugation at $4000 \mathrm{rpm}$ for 5 min by 4 - 5 times. And then, $1 \mu \mathrm{g}$ plasmid DNAs were added into $100 \mu \mathrm{L}$ competent cells in a $2 \mathrm{~mm}$-diameter cuvette. After standing by on ice for $10 \mathrm{~min}$, electroshock was performed at $2500 \mathrm{~V} / \mathrm{cm}, 50 \mu \mathrm{F}$ capacitance and 10 ohms resistance on the Gene PulserX-cell (BioRad Co. California, USA). Afterwards, the cells were rapidly added with $3 \mathrm{~mL}$ RM medium and incubated for $6 \mathrm{~h}$ at $30^{\circ} \mathrm{C}$. Finally, $0.2 \mathrm{~mL}$ of cells were dispensed on RM agar plates containing $200 \mu \mathrm{g} / \mathrm{mL}$ kanamycin. After incubation at $30^{\circ} \mathrm{C}$ for three to four days, the numbers of transformants were first counted. In addition, the entrance of plasmid DNA into the colonies was confirmed with the colony PCR. All the transformation experiments with each plasmid were independently performed in triplicates or more.

\subsection{Construction of the Genome Targeting Plasmids}

First, the full length of the CRISPR locus P1 of Z. mobilis ZM4 was amplified using the primers (Cri01.F and Cri01.R) with the genomic DNAs as template. After digesting with Kpn I and Hind III, the PCR fragment was cloned into the plasmid pBBR1MCS2 digested with the same restriction endonucleases. The resulting plasmid assigned as pCri01, was confirmed by DNA sequencing. And then, three 32-bp sequences with a nearby PAM of TGG at 3'-end were selected as the protospacer at different genomic sites, two located in the gene ZMO0293 and one in ZMO0875. The selected sequence as an alternative spacer was inserted into the pCri01 in displacement of the original spacer 1 and spacer 3, or both via overlapping PCR. The PCR reactions with the Master Mix Kit (Vazyme, Nanjing, China) were performed using pCri01 as template and the overlapping primers (Table S3) as following steps: for the first 6 cycles, pre-denaturation $94^{\circ} \mathrm{C}$ for 4 min, denaturation $94^{\circ} \mathrm{C}$ for 30 sec, annealing at $54^{\circ} \mathrm{C}$ for $30 \mathrm{sec}$, extension at $72^{\circ} \mathrm{C}$ for $6.5 \mathrm{~min}$; and for the subsequent 24 cycles, denaturation $94^{\circ} \mathrm{C}$ for $30 \mathrm{sec}$, annealing at $62^{\circ} \mathrm{C}-68^{\circ} \mathrm{C}$ (for various primer pairs) for $30 \mathrm{sec}$, extension at $72^{\circ} \mathrm{C}$ for $6.5 \mathrm{~min}$ with an additional extension at $72^{\circ} \mathrm{C}$ for $5 \mathrm{~min}$. And then, the PCR products were digested by DpnI (Thermo scientific) and transformed into E. coli DH5 $\alpha$. The resulting genome targeting plasmids were sequenced to confirm the inserted DNA sequence. For targeting the genome, these plasmids (Table S2) were transformed into the ZM4 cells by electroporation as described in the above section. The number of transformants was accounted for each plasmid. For each plasmid, the transformation was independently performed in triplicates.

\section{Results}

\subsection{Organization and Structure of CRISPR-Cas System in Z. mobilis ZM4}

According to the databases CRISPRdb (crispr.u-psud.fr) and CRISPI (www.crispi.it/it/index.php), Z. mobilis ZM4 contains the CRISPR-Cas system with three CRISPR loci named as P1 to 3 and a cas gene cluster. The organization and structure of the CRISPR/Cas system in the genome was present in Figure 1. The CRISPR loci (P1-3) share the identical repeat sequence (GTTCACTGCCGCACAGGCAGCTTAGAAA); and contain the unique spacers interspaced by 8,6 , and 1 , respectively. It is noticeable that the CRISPR P3 is not complete due to the last repeat sequence. The repeat sequence in these CRISPR loci of Z. mobilis ZM4 is completely identical with the other CRISPR arrays from Pseudomonas aeruginosa [15], Pectobacterium atrosepticum [28], Yersinia 


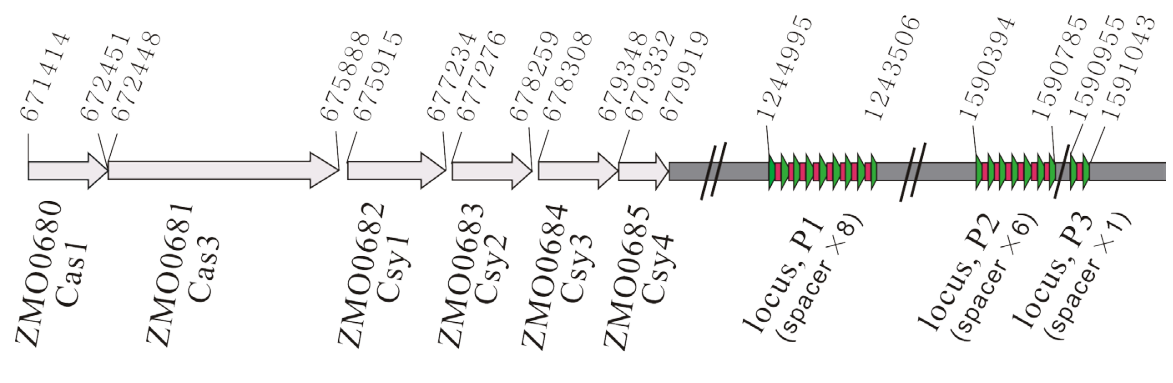

DR: GTTCACTGCCGCACAGGCAGCTTAGAAA

Figure 1. Organization of the Type I-F CRISPR-Cas system of Z. mobilis ZM4. This system is consisted of 3 CRISPR loci (P1-P3) and a far distant cas gene cluster (Cas1, Cas3, Csy1, Csy2, Csy3 and Csy4). The sequence of direct repeat (DR) is present in the box.

pestis [29] and E. coli [15], which should be classified into group 4 [30]. The majority of spacer sequence are 32 or $33 \mathrm{nt}$ in length, none of which matches to the known viruses or plasmids by BLASTn against the Nucleotide Collection database (www.blast.ncbi.nlm.nih.gov/Blast.cgi).

Unlike most CRISPR-Cas systems in the other bacteria or archaea in which the cas gene cluster is located immediately near by the CRISPR locus [3], the cas gene clusterin Z. mobilis ZM4 is far distant from the CRISPR loci in the genome and consisted of six cas genes: cas1, cas3, csy1, csy2, csy3, and csy4 (or cas6f) (Figure 1). The components and organization of the cas gene cluster in Z. mobilis ZM4 are similar with that of $Y$. pestis Z176003 [29]. Accordingly, the CRISPR-Cas system in Z. mobilis ZM4 belongs to Type I-F or Ypest [31].

\subsection{Expression of the CRISPR-Cas System in Z. mobilis ZM4}

In order to confirm if the CRISPR loci in Z. mobilis ZM4 is or not transcribed, a strategy based on the reverse transcription (RT) and PCR reaction was adopted (Figure 2(a)). Two total RNA samples, isolated from the cells growing for 10 and $16 \mathrm{~h}$ in RM broth, were reversely transcribed with each specific primer, e.g. Zm4C1S3.F, Zm4C1S6.R, Zm4C2S2.F or Zm4C2S5.R, which is specific to complement with a specific spacer sequence on the double strands of the CRISPR locus P1 and P2, respectively. First, PCR reaction was performed using the RNA samples as template, indicating that no genomic DNA was contaminated in these RNA samples (Figure 2(b), line 1). And then, the same PCR amplification with the routine 32 cycles was performed with two pairs of primers (ZmC1S3.F/ZmC1S6.R and ZmC2S2.F/ZmC2S5.R for CRISPR loci P1 and P2, respectively). Unexpectedly, the PCR products were obviously observed by the cDNA templates by reversely transcribed either with the forward primer or the reverse primer (Zm4C1S3.F or Zm4C1S6.R for the CRISPR locus P1, and Zm4C2S2.F or Zm4C2S5.R for the CRISPR locus P2). Subsequently, PCR reaction with reduced cycling number (25) was also preformed again. A representative result was shown in Figure 2(b), indicating that both of the cDNA templates reversely transcribed with the forward or reverse primer could be amplified to produce the PCR products. However, higher yield was obtained with the cDNA template from the reverse primer than that from the forward primer under the same condition. These data indicated that the CRISPR arrays of Z. mobilis ZM4 were transcribed on both strands, but with different expression level. The CRISPR locus in Sulfolobus acidocaldarius was also reported to be transcribed on both strands [32]. Conclusively, these experimental evidences indicated that the CRISPR loci are indeed transcribed in Z. mobilis ZM4 under the normal growing condition. Further, we can infer the transcriptional direction and the leader region of the CRISPR loci in this bacterium. Accordingly, the characteristic elements such as TATA box and AT-rich region can be inferred in the upstream region of the CRISPR loci P1 and P2.

Further, the transcripts of six cas genes in Z. mobilis ZM4 growing at various conditions could be easily detected in the previous transcriptional analysis [33] [34]. For example, the relative transcriptional levels of the cas genes are presented in Table 1, which is retrieved from the transcriptome data in the previous studies [35]. These data indicate that the cas genes may be transcribed constitutionally.

\subsection{Immune Defense against the Invader Plasmids in Z. mobilis ZM4}

Since the cas gene cluster and the CRISPR loci are transcribed actively in Z. mobilis ZM4, this system is expected 
a

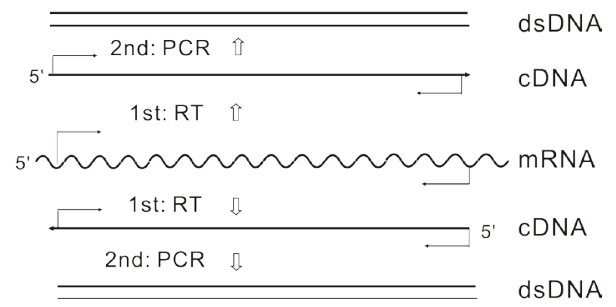

b

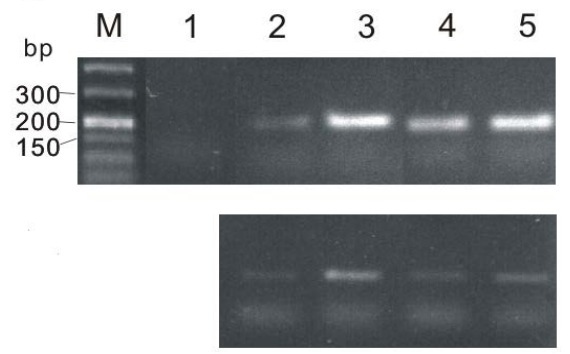

Figure 2. Transcription of the CRISPR loci P1, P2 and P3 of Z. mobilis ZM4. (a) A strategy adopted for identification of the transcription and the transcriptional direction; (b) Electrophoresis analysis of the reverse transcription (RT)-PCR with the RNA sample with PCR cycles of 32 (upper panel) and 25 (lower panel), respectively; lane 1, PCR amplification using the total RNAs as template; lane 2 and lane 3, PCR products using the cDNA templates obtained from the reversely transcriptional reaction using the primers of ZM4C1S3.F and ZM4C1S6.R, respectively. lane 4 and 5, the PCR products using the cDNA templates obtained from the reversely transcriptional reaction using the primers of ZM4C2S2.F and ZM4C2S6.R, respectively.

Table 1. Relative transcription levels of cas genes in Zymomonas mobilis ZM4*.

\begin{tabular}{rcccc}
\hline Gene ID. & $\begin{array}{c}\text { Description } \\
\text { (TIGRFAM) }\end{array}$ & $4 \mathrm{~h}$ & $8 \mathrm{~h}$ & $12 \mathrm{~h}$ \\
\hline ZMO0680 & Cas1 family & $828.42 \pm 69.9$ & $783.52 \pm 52.9$ & $1000.19 \pm 59.2$ \\
ZMO0681 & Cas3 family & $1248.63 \pm 52.0$ & $1327.13 \pm 121.3$ & $1618.38 \pm 109.5$ \\
ZMO0682 & Csy1 family & $2648.84 \pm 279.0$ & $2886.38 \pm 191.7$ & $2887.63 \pm 52.5$ \\
ZMO0683 & Csy2 family & $1969.47 \pm 68.6$ & $1847.80 \pm 99.7$ & $1981.85 \pm 91.3$ \\
ZMO0684 & Csy3 family & $2580.21 \pm 63.6$ & $2149.24 \pm 184.9$ & $2202.51 \pm 138.9$ \\
ZMO0685 & Csy4 family & $2725.74 \pm 122.7$ & $2335.56 \pm 30.9$ & $2195.22 \pm 190.6$ \\
\hline
\end{tabular}

${ }^{*}$ Z. mobilis ZM4 was grown in RM medium at $30^{\circ} \mathrm{C}$ in stationary condition for various times. And 220 g/l glucose was added into the medium at 6 h. The data were obtained from the microarray assay described as before [35].

to be active to defense against the invader DNA elements. However, no virus has been reported to associate with Z. mobilis, so the plasmid-based invader assay was applied to this purpose [13] [36]. First, a series of invader plasmids were constructed (Table S2), with in which the first spacer and the third spacer of CRISPR locus P1 with the deduced PAM site (TGG or GG) at the 3'-end on the target strand were inserted in the shuttering plasmid pBBR1MCS2by overlapped PCR to serve as an artificial protospacer. All the constructed invasion plasmids and the parent plasmid were transformed into the competent cells of ZM4 by electroporation under the same condition. The transformants were selected on the RM agarplates with addition of $200 \mu \mathrm{g} / \mathrm{mL} \mathrm{kanamycin}$. In addition, the transformants were randomly picked up and used to perform PCR, which confirmed entrance of the plasmid DNA into the bacterial cells (data not shown).

Expectedly, the numbers of transformants of the invader plasmids containing the artificial protospacer with PAM motifs (TGG and GG) were significantly less than that of the parent plasmid (without no spacer inserted) (Figure 3(a)). The data of three individual transformation experiments were given in Figure 3(b). Reduce of the relative transformation rate was contributed to the immune defense of the invader plasmid DNA by the native CRISPR-Cas system in the bacterial cells [13]. However, the immune activity is less effective with the PAM motif of TGG than GG because the transformation rate trends to about 1\% - 4\% with GG as PAM in comparison to $>20 \%$ with TGG as PAM (Figure $3(\mathrm{~b})$ ). Based on the structural model of the Cascade complex revealed in the Type I CRISPR-Cas system [7] [8], the Cascade complex with the crRNA biogenerated from the CRISPR transcripts in Z. mobilis ZM4 would be formed, and then guide to target the protospacer (Figure 3(c)).

In addition, the invader plasmid DNAs were still escaped from the immune interference by the CRISPR-Cas system (Figure 3), which is consistence with the previous studies with the archaeal CRISPR-Cas system [13]. 

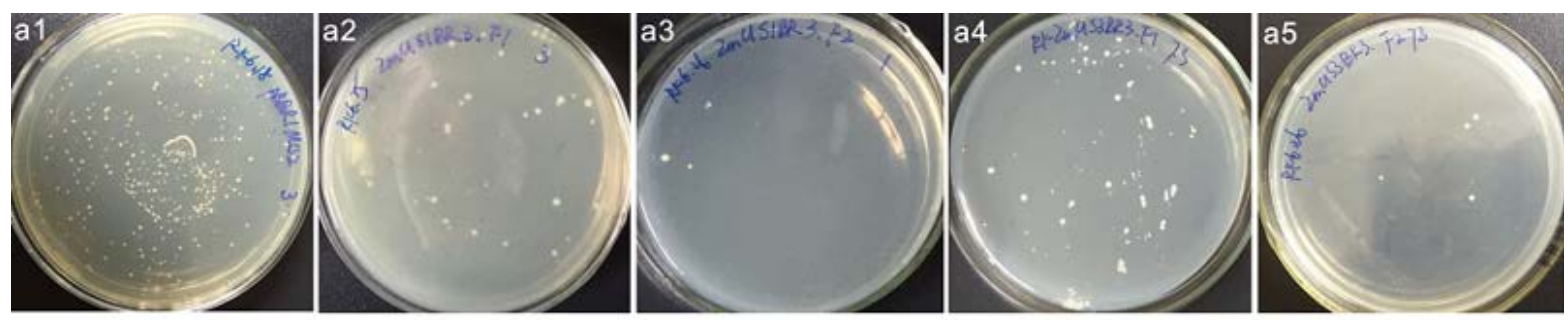

(b)

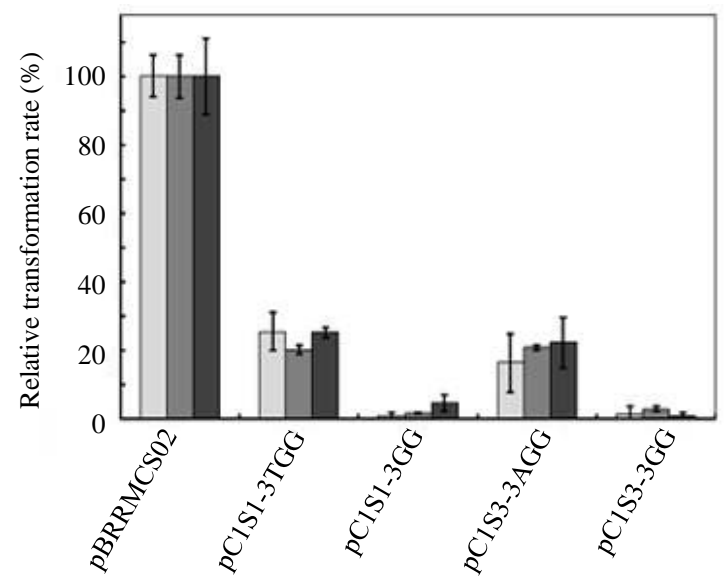

(c)

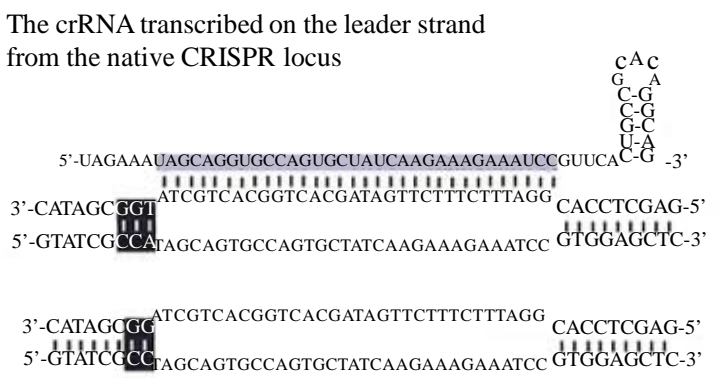

Protospacer with PAM TGG and GG inserted in the invader plasmids

Figure 3. The plasmid-based interference activity of CRISPR-Cas system in Z. mobilis ZM4 with the crRNA generated from the leader strand. (a) 1-5 presented the representative transformation plates using the control plasmid pBRRMCS02 and the invader plasmids of pC1S1-3TGG, pC1S1-3GG, pC1S3-3AGG and pC1S3-3GG, respectively. The invader plasmids were constructed in pBRRMCS02 by insertion of a protospacer which was consisted of spacer 1 or 3 from the CRISPR locus P1 and the PAM motif of TGG or GG; (b) The transformation rates of the invader plasmids relative to the control plasmid pBRRMCS2 (100\%). The data were obtained from three independent experiments.

\subsection{Targeting the Genome with the Artificial CRISPR Array}

In order to confirm the immune function of the CRISPR-Cas system in Z. mobilis ZM4, a series of targeting plasmids were constructed (Table S2), in which the selected target sequences at different genomic sites were cloned into the CRISPR array P1 in placement of the original spacer 1 and/or 3. These plasmids are expected to drive the modified CRISPR array to express and to generate the special crRNA in the bacterial cells. After transformation into cells, the targeting plasmids led to almost no transformant to form on the kanamycin-containing RM agar plates (Figure 4(a)). In contrast, number of the transformants was much more with the control plasmid pCri01 which hosting a native CRISPR locus P1 (Figure 4(b)). These data indicate that the crRNA derived from the modified CRISPR array with spacer sequence targeting to the specific genomic sites in the plasmids could guide to cut the genome at the target protospacer site. As a result, the double-stranded breakage in the genome made by the interference activity will lead to the cells to die [31]. Noticeable, the transformation rate is usually less than $4 \%$ with various spacers or location in the CRISPR array (Figure 4). In contrast, the transformation rate to target the invader plasmids is in the range of about $20 \%$ when T/AGG PAM motifs were used (Figure 3). Therefore, the immune activity to target the genome is stronger than to target the invader plasmids under this condition.

\section{Discussion}

In terms of the components and organization of the CRISPR-Cas system, the CRISPR-Cas system of Z. mobilis ZM4 should be classified into to the Type I-F or Ypest [31]. The same type of CRISPR-Cas systems also occurs in the other Z. mobilis strains with the genome sequenced, like CP4, ATCC 29191, NCIMB 11163, and ATCC10988 (Table S1). A cas gene cluster (encoding Cas1, Cas2, Csy1-4) also occurs in these strains but far from 

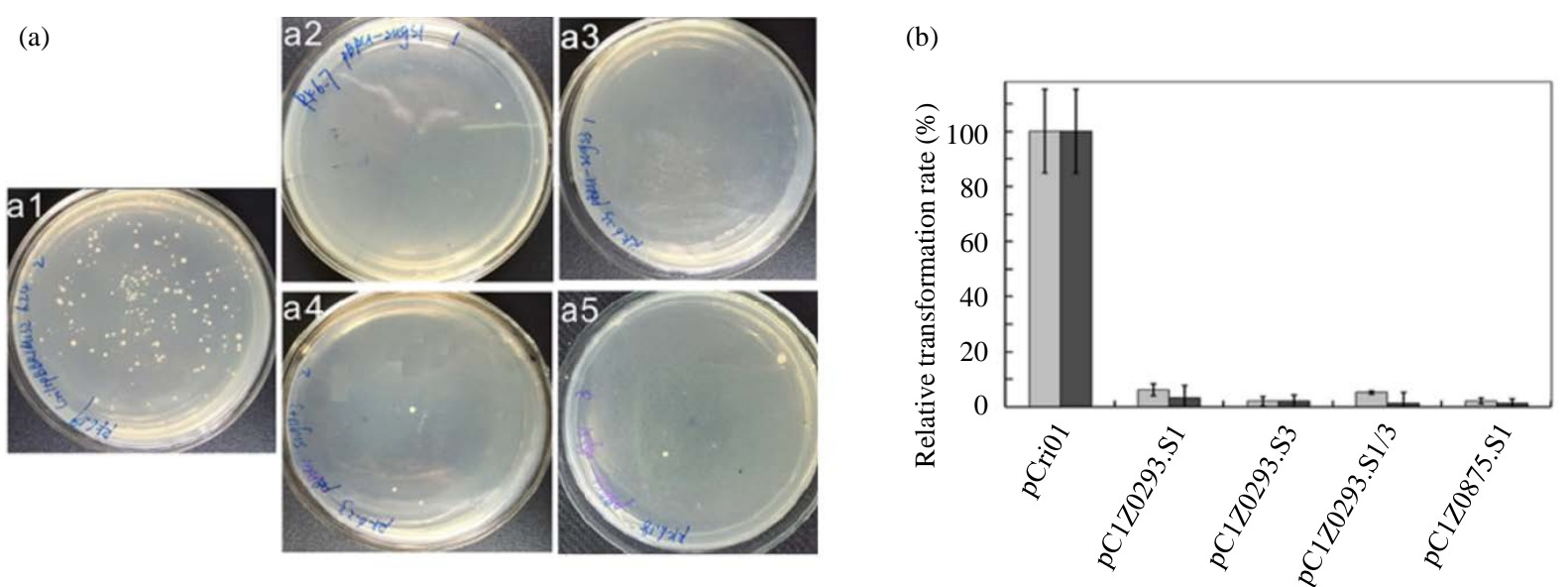

Figure 4. Genome targeting with the artificial CRISPR array in Z. mobilis ZM4. (a) 1-5 presented the representative transformation plates with the control plasmid pCri01 and the targeting plasmids of pC1Z0293.S1, pC1Z0293.S3; pC1Z0293.S1/3, and pC1Z0875.S1, respectively. The targeting plasmids were constructed by insertion of the spacer sequences selected from various genome regions (two from ZMO0293, one from ZMO0875) in replacement of the original spacer 1 and/or 3 in the CRISPR locus P1 in pBRRMCS02; (b) The transformation rates of the targeting plasmids relative to the control plasmid pCri01 (100\%), which is derived from two independent experiments.

the location of CRISPR arrays. It is noted that a cas gene encoding Csy4 is missed in the genome of ATCC 10988. In the above Type I-F CRISPR-Cas systems, the directed repeat sequences are $28 \mathrm{bp}$ in length with the almost identity, which belongs to the group 4 as assigned by Kunin et al. [30]. In contrast, the strain ATCC 29192 possesses a Type I-E CRISPR-Cas system in its genome. In addition, a Type I-C CRISPR-Cas system also occurs in the cryptic plasmid of strains ATCC 29191 and NCIMB 11163, respectively. However, various numbers and sequence content of spacers occur in these CRIPSR-Cas systems of the different $Z$. mobilis strains. By BLASTn against the NCBI database, these spacer sequences do not match any known sequence of viruses and plasmids. Based on the cas gene organization and the different sequences of CRISPR arrays existing in the Z. mobilis strains, the CRISPR-Cas systems may be acquired by Z. mobilis through the horizontal gene transfer [37].

For the type I-F CRISPR-Cas system, functional studies mainly focused on $P$. aeruginosa and $P$. atrosepticum [24] [26]. Occasionally, the CRISPR-Cas systems may not confer the immune interference against the foreign DNA elements, such as in the clinic isolates of $P$. aeruginosa [15]. So our purpose is to examine if this system does or not work in the ethanologenic bacteria Z. mobilis. First, the transcription and direction of the CRISPR locus in Z. mobilis ZM4 were experimentally identified by RT-PCR. Unexpectedly, the CRISPR arrays are transcribed on both strands (Figure 2). The similar status was observed in Sulfolobus [32]. Looking into the upstream region of the CRISPR arrays of P1 or P2 on the leading strand, a leader sequence could be identified with the promoter motifs, like TATA-box and T/A-rich region. In contrast, no leader sequence with the promoter properties could be inferred from the complement strands nearby the CRISPR arrays. So the transcripts from the complementary strands detected here may be due to the reading-through of transcription of the downstream gene. In E. coli, expression of the CRISPR array is revealed to be highly regulated [38]. In addition, the cas genes seem to express constitutionally which is inferred from the previous transcriptomic analysis in Z. mobilis ZM4 [33]-[35]. Taken together, the CRISPR-Cas system in ZM4 can be expressed under the normal growing condition. In E. coli, the expression of Type I-F CRISPR-Cas system was also recognized to be expressed constitutionally, but the other Type I-E CRISPR-Cas seem no expression under the normal growing condition [25].

Further, the occurrence of CRISPR-Cas activity in Z. mobilis ZM4 was demonstrated for the first time via the artificial systems like silence of the invader plasmids or genome targeting. In the immune processing, PAM motif and its position are essential for the interference function and different PAM sites has been revealed to be effective in various CRISPR-Cas systems [39]. Therefore, two PAM motifs (GG and TGG), which were recently demonstrated to be functional in the other Type I-F CRISPR-Cas systems [26] [31], were applied to this work. The plasmid-based analysis demonstrated both PAM motifs of GG and AGG were effective in the immune interference in Z. mobilis ZM4, suggesting that the conservative mechanism of immune interference occurred 
across the Type I-F CRISPR-Cas systems in various bacteria. In terms of the relative transformation rate, the PAM motif of GG seems more effective than TGG or AGG (Figure 3). These results suggested that PAM motif (GG) is the prior base to be recognized by the Cascade complex, which is consistent with the in vitro experimental evidence by Rollins et al. [39]. In fact, the other PAM motifs were also reported to function effectively in the other Type I-F CRISPR-Cas systems [25] [26]. Further, crRNA biogenerated from the artificial CRISPR array with the spacer sequence corresponding the specific genomic sites could guide the Cascade complex to efficiently cut the specific genomic site, resulting in almost no transformant formed on the selected agarose plates (Figure 4). This is totally different from the situation in eukaryote cells in which the double breakage of genomic DNA made by the Cas9/gRNA could be rejoined again [10]. Therefore, we suppose that the bacteria, like Z. mobilis ZM4, may be lack of rejoining function to heal the double breakage.

However, the escape of immune interference was also observed in the Z. mobilis ZM4, especially in plasmid based assay. The previous studies using an archaeal CRISPR system obtained similar results, which was attributed to the mutation in the CRISPR array [13]. In this work, we demonstrated that the genome targeting assay led to less escape in immune interference than the plasmid-based assay. We suggest that another reason for this deviation may be aroused from the transcription level of the CRISPR-Cas system, since the modified CRISPR array in the multiple copy plasmid is expected to express more copies of crRNA. In E. coli, over expression of a cas gene (casE) could increase the crRNA level in the cells, and leading to express the interference activity [7]. Therefore, some CRISPR-Cas systems exhibiting less or no activity in immune interference may be due to the lower or no expression of CRISPR-Cas system.

\section{Conclusion}

Conclusively, our findings demonstrated that the Type I-F CRISPR-Cas system of Z. mobilis ZM4 is expressed and active in immune interference under the normal growing condition. Further, both strands of the CRISPR array can be transcribed but differentially.

\section{References}

[1] Bhaya, D., Davison, M. and Barrangou, R. (2011) CRISPR-Cas Systems in Bacteria and Archaea: Versatile Small RNAs for Adaptive Defense and Regulation. Annual Review of Genetics, 45, 273-297. http://dx.doi.org/10.1146/annurev-genet-110410-132430

[2] Haft, D.H., Selengut, J., Mongodin, E.F. and Nelson, K.E. (2005) A Guild of 45 CRISPR-Associated (Cas) Protein Families and Multiple CRISPR/Cas Subtypes Exist in Prokaryotic Genomes. PLoS Computational Biology, 1, e60. http://dx.doi.org/10.1371/journal.pcbi.0010060

[3] Makarova, K.S., Haft, D.H., Barrangou, R., Brouns, S.J.J., Charpentier, E., Horvath, P., Moineau, S., Mojica, F.J.M., Wolf, Y.I., Yakunin, A.F., van der Oost, J. and Koonin, E.V. (2011) Evolution and Classification of the CRISPR-Cas Systems. Nature Reviews Microbiology, 9, 467-477. http://dx.doi.org/10.1038/nrmicro2577

[4] Marraffini, L.A. and Sontheimer, E.J. (2008) CRISPR Interference Limits Horizontal Gene Transfer in Staphylococci by Targeting DNA. Science, 322, 1843-1845. http://dx.doi.org/10.1126/science.1165771

[5] Nuñez, J.K., Lee, A.S.Y., Engelman, A. and Doudna, J.A. (2015) Integrase-Mediated Spacer Acquisition during CRISPR-Cas Adaptive Immunity. Nature, 519, 193-198. http://dx.doi.org/10.1038/nature14237

[6] Fineran, P.C., Gerritzen, M.J., Suarez-Diez, M., Kunne, T., Boekhorst, J., van Hijum, S.A., Staals, R.H. and Brouns, S.J. (2014) Degenerate Target Sites Mediate Rapid Primed CRISPR Adaptation. Proceedings of the National Academy of Sciences of the United States of America, 111, E1629-E1638. http://dx.doi.org/10.1073/pnas.1400071111

[7] Pougach, K., Semenova, E., Bogdanova, E., Datsenko, K.A., Djordjevic, M., Wanner, B.L. and Severinov, K. (2010) Transcription, Processing and Function of CRISPR Cassettes in Escherichia coli. Molecular Microbiology, 77, 13671379. http://dx.doi.org/10.1111/j.1365-2958.2010.07265.x

[8] Wiedenheft, B., Lander, G.C., Zhou, K., Jore, M.M., Brouns, S.J., van der Oost, J., Doudna, J.A. and Nogales, E. (2011) Structural of the RNA-Guided Surveillance Complex from a Bacterial Immune System. Nature, 477, 486-489. http://dx.doi.org/10.1038/nature10402

[9] Wiedenheft, B., van Duijn, E., Bultema, J.B., Waghmare, S.P., Zhou, K., Barendregt, A., Westphal, W., Heck, A.J.R., Boekema, E.J., Dickman, M.J. and Doudna, J.A. (2011) RNA-Guided Complex from a Bacterial Immune System Enhances Target Recognition through Seed Sequence Interactions. Proceedings of the National Academy of Sciences of the United States of America, 108, 10092-10097. http://dx.doi.org/10.1073/pnas.1102716108

[10] Mali, P., Yang, L., Esvelt, K.M., Aach, J., Guell, M., Dicarlo, J.E., Norville, J.E. and Church G.M. (2013) RNA- 
Guided Human Genome Engineering via Cas9. Science, 339, 823-826. http://dx.doi.org/10.1126/science.1232033

[11] Jiang, W.Y., Bikard, D., Cox, D., Zhang, F. and Marraffini, L.A. (2013) RNA-Guided Editing of Bacterial Genomes Using CRISPR-Cas Systems. Nature Biotechnology, 31, 233-239. http://dx.doi.org/10.1038/nbt.2508

[12] Mojica, F.J.M., Diez-Villasenor, C., Garcia-Martinez, J. and Almendros, C. (2009) Short Motif Sequences Determine the Targets of the Prokaryotic CRISPR Defense System. Microbiology, 155, 733-740. http://dx.doi.org/10.1099/mic.0.023960-0

[13] Fischer, S., Maier, L.K., Stoll, B., Brendel, J., Fischer, E., Pfeiffer, F., Dyall-Smith, M. and Marchfelder, A. (2012) An Archaeal Immune System Can Detect Multiple Protospacer Adjacent Motifs (PAMs) to Target Invader DNA. The Journal of Biological Chemistry, 287, 33351-33365. http://dx.doi.org/10.1074/jbc.M112.377002

[14] Li, M., Wang, R. and Xiang, H. (2014) Haloarcula hispanica CRISPR Authenticates PAM of a Target Sequence to Prime Discriminative Adaptation. Nucleic Acids Research, 42, 7226-7235. http://dx.doi.org/10.1093/nar/gku389

[15] Cady, K.C., White, A.S., Hammond, J.H., Abendroth, M.D., Karthikeyan, R.S., Lalitha, P., Zegans, M.E. and O’Toole, G.A. (2011) Prevalence, Conservation and Functional Analysis of Yersinia and Escherichia CRISPR Regions in Clinical Pseudomonas aeruginosa Isolates. Microbiology, 157, 430-437. http://dx.doi.org/10.1099/mic.0.045732-0

[16] He, M.X., Wu, B., Qin, H., Ruan, Z.Y., Tan, F.R., Wang, J.L., Shui, Z.X., Dai, L.C., Zhu, Q.L., Pan, K., Tang, X.Y., Wang, W.G. and Hu, Q.C. (2014) Zymomonas mobilis: A Novel Platform for Future Biorefineries. Biotechnology for Biofuels, 7, 101. http://dx.doi.org/10.1186/1754-6834-7-101

[17] Seo, J.S., Chong, H., Park, H.S., Yoon, K.O., Jung, C., Kim, J.J., Hong, J.H., Kim, H., Kim, J.H., Kil, J.I., Park, C.J., Oh, H.M., Lee, J.S., Jin, S.J., Um, H.W., Lee, H.J., Oh, S.J., Kim, J.Y., Kang, H.L., Lee, S.Y., Lee, K.J. and Kang, H.S. (2005) The Genome Sequence of the Ethanologenic Bacterium Zymomonas mobilis ZM4. Nature Biotechnology, 23, 63-68. http://dx.doi.org/10.1038/nbt1045

[18] Pappas, K.M., Kouvelis, V.N., Saunders, E., Brettin, T.S., Bruce, D., Detter, C., Balakireva, M., Han, C.S., Savvakis, G., Kyrpides, N.C. and Typas, M.A. (2011) Genome Sequence of the Ethanol-Producing Zymomonas mobilis subsp. Mobilis Lectotype ATCC 10988. Journal of Bacteriology, 193, 5051-5052. http://dx.doi.org/10.1128/JB.05395-11

[19] Kouvelis, V.N., Teshima, H., Bruce, D., Detter, C., Tapia, R., Han, C., Tampakopoulou, V.O., Goodwin, L., Woyke, T., Kyrpides, N.C., Typas, M.A. and Pappas, K.M. (2014) Finished Genome of Zymomonas mobilis subsp. Mobilis Strain CP4, an Applied Ethanol Producer. Genome Announce, 2, e00845-13. http://dx.doi.org/10.1128/JB.05395-11

[20] Desiniotis, A., Kouvelis, V.N., Davenport, K., Bruce, D., Detter, C., Tapia, R., Han, C., Goodwin, L.A., Woyke, T. and Kyrpides, N.C. (2012) Complete Genome Sequence of the Ethanol-Producing Zymomonas mobilis subsp. Mobilis Centrotype ATCC 29191. Journal of Bacteriology, 194, 5966-5967. http://dx.doi.org/10.1128/JB.01398-12

[21] Kouvelis, V.N., Saunders, E., Brettin, T.S., Bruce, D., Detter, C., Han, C., Typas, M.A. and Pappas, K.M. (2009) Complete Genome Sequence of the Ethanol Producer Zymomonas mobilis NCIMB 11163. Journal of Bacteriology, 191, 7140-7141. http://dx.doi.org/10.1128/JB.01084-09

[22] Kouvelis, V.N., Davenport, K.W., Brettin, T.S., Bruce, D., Detter, C., Han, C.S., Nolan, M., Tapia, R., Damoulaki, A., Kyrpides, N.C., Typas, M.A. and Pappas, K.M. (2011) Genome Sequence of the Ethanol-Producing Zymomonas mobilis subsp. Pomaceaelectotype ATCC 29192. Journal of Bacteriology, 193, 5049-5050. http://dx.doi.org/10.1128/JB.05273-11

[23] Kovach, M.E., Elzer, P.H., Hill, D.S., Robertson, G.T., Farris, M.A., Roop, R.M. and Peterson, K.M. (1995) Four New Derivatives of the Broad-Host-Range Cloning Vector pBBR1MCS, Carrying Different Antibiotic-Resistance Cassettes. Gene, 166, 175-176. http://dx.doi.org/10.1016/0378-1119(95)00584-1

[24] Richter, C., Dy, R.L., McKenzie, R.E., Watson, B.N.J., Taylor, C., Chang, J.T., McNeil, M.B., Staals, R.H.J. and Fineran, P.C. (2014) Priming in the Type I-F CRISPR-Cas System Triggers Strand-Independent Spacer Acquisition, Bi-Directionally from the Primed Protospacer. Nucleic Acids Research, 42, 8516-8526. http://dx.doi.org/10.1093/nar/gku527

[25] Almendros, C., Guzman, N.M., Diez-Villasenor, C., Garcia-Martinez, J. and Mojica, F.J.M. (2012) Target Motifs Affecting Natural Immunity by a Constitutive CRISPR-Cas System in Escherichia coli. PLoS ONE, 7, e50797. http://dx.doi.org/10.1371/journal.pone.0050797

[26] Cady, K.C., Bondy-Denomy, J., Heussler, G.E., Davidson, A.R. and O’Toole A. (2012) The CRISPR/Cas Adaptive Immune System of Pseudomonas aeruginosa Mediates Resistance to Naturally Occurring and Engineered Phages. Journal of Bacteriology, 194, 5728-5738. http://dx.doi.org/10.1128/JB.01184-12

[27] Okamoto, T. and Nakamura, K. (1992) Simple and Highly Efficient Transformation Method for Zymomonas mobilis: Electroporation. Bioscience, Biotechnology \& Biochemistry, 56, 833-833. http://dx.doi.org/10.1271/bbb.56.833

[28] Pyzybilski, R., Richter, C., Gristwood, T., Clulow, J.S., Vercoe, R.B. and Fineran, P.C. (2011) Csy4 Is Responsible for CRISPR RNA Processing in Paectobacterium atrosepticum. RNA Biology, 8, 517-528. http://dx.doi.org/10.4161/rna.8.3.15190 
[29] Pourcel, C., Salvignol, G. and Vergnaud, G. (2005) CRISPR Elements in Yersinia pestis Acquire New Repeats by Preferential Uptake of Bacteriophage DNA, and Provide Additional Tools for Evolutionary Studies. Microbiology, 151, 653-663. http://dx.doi.org/10.1099/mic.0.27437-0

[30] Kunin, V., Sorek, R. and Hugenholtz, P. (2007) Evolutionary Conservation of Sequence and Secondary Structures in CRISPR Repeats. Genome Biology, 8, R61. http://dx.doi.org/10.1186/gb-2007-8-4-r61

[31] Vercoe, R.B., Chang, J.T., Dy, R.L., Taylor, C., Gristwood, T., Clulow, J.S., Richter, C., Przybilski, R., Pitman, A.R. and Fineran, P.C. (2013) Cytotoxic Chromosomal Targeting by CRISPR/Cas Systems Can Reshape Bacterial Genomes and Expel or Remodel Pathogenicity Islands. PLoS Genetics, 9, e1003454. http://dx.doi.org/10.1371/journal.pgen.1003454

[32] Lillestøl, R.K., Shah, S.A., Brügger, K., Redder, P., Phan, H., Christiansen, J. and Garrett, R.A. (2009) CRISPR Families of Thecrenarchaeal Genus Sulfolobus: Bidirectional Transcription and Dynamic Properties. Molecular Microbiology, 72, 259-272. http://dx.doi.org/10.1111/j.1365-2958.2009.06641.x

[33] He, M.X., Wu, B., Shui, Z.X., Hu, Q.C., Wang, W.G., Tan, F.R., Tang, X.Y., Zhu, Q.L., Pan, K., Li, Q. and Su, X.H. (2012) Transcriptome Profiling of Zymomonas mobilis under Ethanol Stress. Biotechnology for Biofuels, 5, 75. http://dx.doi.org/10.1186/1754-6834-5-75

[34] He, M.X., Wu, B., Shui, Z.X., Hu, Q.C., Wang, W.G., Tan, F.R., Tang, X.Y., Zhu, Q.L., Pan, K., Li, Q. and Su, X.H. (2012) Transcriptome Profiling of Zymomonas mobilis under Furfural Stress. Applied Microbiology and Biotechnology, 95, 189-199. http://dx.doi.org/10.1007/s00253-012-4155-4

[35] Zhang, K., Shao, H.H., Cao, Q.H., He, M.X., Wu, B. and Feng, H. (2015) Transcriptional Analysis of Adaptation to High Glucose Concentrations in Zymomonas mobilis. Applied Microbiology and Biotechnology, 99, 2009-2022. http://dx.doi.org/10.1007/s00253-014-6342-y

[36] Elmore, J.R., Yokooji, Y., Sato, T., Olson, S., Glover, CV., Graveley, B.R., Atomi, H., Terns, R.M. and Terns, M.P. (2013) Programmable Plasmid Interference by the CRISPR-Cas System in Thermococcus kodakarensis. RNA Biology, 10, 828-840. http://dx.doi.org/10.4161/rna.24084

[37] Portillo, M.C. and Gonzalez, J.M. (2009) CRISPR Elements in Three Theromococcales: Evidence for Associated Horizontal Gene Transfer in Pyrococcus furiosus. Journal of Applied Genetics, 50, 421-430. http://dx.doi.org/10.1007/BF03195703

[38] Pul, Ü., Wurm, R., Arslan, Z., Geissen, R., Hofmann, N. and Wagner, R. (2010) Identification and Characterization of E. coli CRISPR-Cas Promoters and Their Silencing by H-NS. Molecular Microbiology, 75, 1495-1512. http://dx.doi.org/10.1111/j.1365-2958.2010.07073.x

[39] Rollins, M.F., Schuman, J.T., Paulus, K., Bukhari, H.S.T. and Wiedenheft, B. (2015) Mechanism of Foreign DNA Recognition by a CRISPR RNA-Guided Surveillance Complex from Pseudomonas aeruginosa. Nucleic Acids Research, 43, 2216-2222. http://dx.doi.org/10.1093/nar/gkv094 
Supporting Information

Table S1. Characteristics of CRISPR-Cas systems in various strains of Zymomonas mobilis.

\begin{tabular}{|c|c|c|c|c|c|c|c|}
\hline Strains & CRISPR loci* & Spacer & Repetitive sequence & Strand & Cas gene & Type & Reference \\
\hline \multirow{3}{*}{$\begin{array}{l}\text { Z. mobilis } \\
\text { (ZM4) } \\
\text { ATCC3182 } \\
1\end{array}$} & $\begin{array}{l}\text { NC_006526_ } \\
1\end{array}$ & 8 & GTTCACTGCCGCACAGGCAGCTTAGAAA & + & \multirow{3}{*}{$\begin{array}{l}\text { cas } 1, \text { cas } 3, \\
\text { csy1, csy2, } \\
\text { csy3, csy4 }\end{array}$} & \multirow{3}{*}{$\mathrm{I}-\mathrm{F}$} & \multirow{3}{*}{$\begin{array}{l}\text { Seo et al. } \\
\text { (2005) [17] }\end{array}$} \\
\hline & NC_006526_ & 6 & GTTCACTGCCGCACAGGCAGCTTAGAAA & + & & & \\
\hline & $\begin{array}{l}\text { NC_006526_ } \\
3\end{array}$ & 1 & GTTCACTGCCGCACAGGCAGCTTAGAAA & + & & & \\
\hline \multirow{4}{*}{$\begin{array}{l}\text { Z. mobilis } \\
\text { ATCC1098 } \\
8\end{array}$} & $\begin{array}{l}\text { NC_017262_ } \\
1\end{array}$ & 6 & GTTCACTGCCGCACAGGCAGCTTAGAAA & - & \multirow{4}{*}{$\begin{array}{l}\text { cas } 1, \text { cas } 3 \\
\text { csy1, csy2, } \\
\text { csy3 }\end{array}$} & \multirow{4}{*}{$\mathrm{I}-\mathrm{F}$} & \multirow{4}{*}{$\begin{array}{l}\text { Pappas et } \\
\text { al. }(2011) \\
{[18]}\end{array}$} \\
\hline & $\begin{array}{l}\text { NC_017262_ } \\
2\end{array}$ & 1 & $\begin{array}{l}\text { CCAGAAATACTGCACTCGCTGTAATAGCCC } \\
\text { CGATCTCTCAC }\end{array}$ & + & & & \\
\hline & $\begin{array}{l}\text { NC_017262_ } \\
3\end{array}$ & 3 & ACTGCCGCACAGGCAGCTTAGAAA & + & & & \\
\hline & NC_017262_- & 8 & GTTCACTGCCGCACAGGCAGCTTAGAAA & - & & & \\
\hline \multirow{3}{*}{$\begin{array}{l}\text { Z. mobilis } \\
\text { CP4 }\end{array}$} & $\begin{array}{l}\text { NC_022900_ } \\
1\end{array}$ & 7 & TTTCTAAGCTGCCTGTGCGGCAGTGAAC & + & \multirow{3}{*}{$\begin{array}{l}\text { cas } 1, \text { cas } 3 \\
\text { csy1, csy2, } \\
\text { csy3, csy } 4\end{array}$} & \multirow{3}{*}{$\mathrm{I}-\mathrm{F}$} & \multirow{3}{*}{$\begin{array}{l}\text { Kouvelis et } \\
\text { al. (2014) } \\
\text { [19] }\end{array}$} \\
\hline & $\begin{array}{l}\text { NC_022900_ } \\
2\end{array}$ & 4 & TTTCTAAGCTGCCTGTGCGGCAGTGAAC & - & & & \\
\hline & $\begin{array}{l}\text { NC_022900_ } \\
3\end{array}$ & 5 & TTTCTAAGCTGCCTGTGCGGCAGTGAAC & + & & & \\
\hline \multirow{3}{*}{$\begin{array}{l}\text { Z. mobilis } \\
\text { ATCC2919 } \\
1\end{array}$} & $\begin{array}{l}\text { NC_018145_ } \\
1\end{array}$ & 3 & GTTCACTGCCGCACAGGCAGCTTAGAAAA & - & \multirow{3}{*}{$\begin{array}{l}\text { cas } 1, \text { cas } 3 \\
\text { csy1, csy2, } \\
\text { csy3, csy4 }\end{array}$} & \multirow{3}{*}{$\mathrm{I}-\mathrm{F}$} & \multirow{3}{*}{$\begin{array}{l}\text { Desiniotis } \\
\text { et al. }(2012 \\
\text { [20] }\end{array}$} \\
\hline & $\begin{array}{l}\text { NC_018145_ } \\
2\end{array}$ & 3 & GTTCACTGCCGCACAGGCAGCTTAGAAA & + & & & \\
\hline & $\begin{array}{l}\text { NC_018145_ } \\
3\end{array}$ & 8 & GTTCACTGCCGCACAGGCAGCTTAGAAA & - & & & \\
\hline \multirow{4}{*}{$\begin{array}{l}\text { Z. mobilis } \\
\text { NCIMB } \\
11163\end{array}$} & $\begin{array}{l}\text { NC_013355_ } \\
1\end{array}$ & 13 & GTTCACTGCCGCACAGGCAGCTTAGAAA & - & & & \multirow{4}{*}{$\begin{array}{l}\text { Kouvelis et } \\
\text { al. (2009) } \\
\text { [21] }\end{array}$} \\
\hline & $\begin{array}{l}\text { NC_013355_ } \\
2\end{array}$ & 16 & GTTCACTGCCGCACAGGCAGCTTAGAAA & + & $\begin{array}{l}\text { cas1, cas3, } \\
\text { csy1, csy2, } \\
\text { csy3, csy4 }\end{array}$ & $\mathrm{I}-\mathrm{F}$ & \\
\hline & $\begin{array}{l}\text { NC_013355_ } \\
3\end{array}$ & 29 & GTTCACTGCCGCACAGGCAGCTTAGAAA & - & & & \\
\hline & $\begin{array}{l}\text { NC_013357_ } \\
1 \\
\text { (plasmid) }\end{array}$ & 49 & $\begin{array}{l}\text { GTCGCCTCCTTCGCGGAGGCGTGGATTGAA } \\
\text { AC }\end{array}$ & + & $\begin{array}{l}\text { cas } 1, \text { cas } 2, \\
\text { cas } 3, \text { cas } 4 \\
\text { csd } 1, \text { csd } 2\end{array}$ & $\mathrm{I}-\mathrm{C}$ & \\
\hline \multirow{4}{*}{$\begin{array}{l}\text { Z. mobilis } \\
\text { ATCC2919 } \\
2\end{array}$} & $\begin{array}{l}\text { NC_015709_ } \\
1\end{array}$ & 1 & GTTCATCCCCGCGTGGGCGGGGAACAC & + & \multirow{3}{*}{$\begin{array}{l}\text { cas } 1, \text { cas } 2, \\
\text { cas5, cse } 1, \\
\text { cse } 2, \text { cse } 3, \\
\text { cse } 4\end{array}$} & \multirow{3}{*}{ I-E } & \multirow{4}{*}{$\begin{array}{l}\text { Kouvelis et } \\
\text { al. (2011) } \\
{[22]}\end{array}$} \\
\hline & $\begin{array}{l}\text { NC_015709_ } \\
2\end{array}$ & 11 & CGGTTCATCCCCGCGTGGGCGGGGAACAC & + & & & \\
\hline & $\begin{array}{l}\text { NC_015709_ } \\
3\end{array}$ & 17 & CGGTTCATCCCCGCGTGGGCGGGGAACAC & + & & & \\
\hline & $\begin{array}{l}\text { NC_015715_ } \\
1 \text { (plasmid) }\end{array}$ & 16 & $\begin{array}{l}\text { GTTTCAATCCACGCCTCCGCGAAGGAGGCG } \\
\text { AC }\end{array}$ & + & $\begin{array}{l}\text { cas } 1, \text { cas } 2, \\
\operatorname{cas} 3, \operatorname{cas} 4 \\
\operatorname{cs} 11, \operatorname{cs} d 2\end{array}$ & $\mathrm{I}-\mathrm{C}$ & \\
\hline
\end{tabular}

"The name of CRISPR loci is adopted following the CRISPR database (http://crispr.u-psud.fr/). 
Table S2. Bacterial strains and plasmids used in this work.

\begin{tabular}{|c|c|c|}
\hline Strains/plasmids & Genotype/phenotype & Reference \\
\hline \multicolumn{3}{|l|}{ Strains } \\
\hline Z. mobilis ZM4 & Wild type & From ATCC \\
\hline E. coli DH5 $\alpha$ & Used for cloning & The lab stock \\
\hline \multicolumn{3}{|l|}{ Plasmids } \\
\hline pBBR1MCS2 & The broad-host-range vector, $\mathrm{kan}^{\mathrm{R}}$ & Kovach et al. (1995) [23] \\
\hline pC1S1-3TGG & $\begin{array}{l}\text { The spacer } 1 \text { of ZM4 CRISPR locus P1 with the PAM (TGG) at 3'-end in } \\
\text { pBBR1MCS2 }\end{array}$ & This study \\
\hline pC1S1-3GG & $\begin{array}{l}\text { The spacer } 1 \text { of ZM4 CRISPR locus P1 with the PAM (GG) at 3'-end in } \\
\text { pBBR1MCS2 }\end{array}$ & This study \\
\hline pC1S3-3AGG & $\begin{array}{l}\text { The spacer } 3 \text { of ZM4 CRISPR locus P1 with the PAM (AGG) at 3'-end in } \\
\text { pBBR1MCS2 }\end{array}$ & This study \\
\hline pC1S3-3GG & $\begin{array}{l}\text { The spacer } 3 \text { of ZM4 CRISPR locus P1 with the PAM (GG) at 3'-end in } \\
\text { pBBR1MCS2 }\end{array}$ & This study \\
\hline pCri01 & $\begin{array}{l}\text { Derived from pBBR1MCS2 containing the ZM4 CRISPR locus } 1 \text { with } \\
\text { 5'-and 3'-regions }\end{array}$ & This study \\
\hline pC1Z0293.S1 & $\begin{array}{l}\text { In pCri01, the spacer } 1 \text { is replaced with a 32-bp target sequence from the } \\
\text { ZM4 gene ZMO0293 }\end{array}$ & This study \\
\hline pC1Z0293.S3 & $\begin{array}{l}\text { In pCri01, the spacer } 3 \text { is replaced with another 32-bp target sequence from } \\
\text { the gene ZMO0293 }\end{array}$ & This study \\
\hline pC1Z0293.S1/3 & $\begin{array}{l}\text { In pCri01, the spacer } 1 \text { and } 3 \text { are replaced with the above two 32-bp target } \\
\text { sequences from ZMO0293 }\end{array}$ & This study \\
\hline pC1Z0875.S1 & $\begin{array}{l}\text { In pCri01, the spacer } 1 \text { was replaced with a 32-bp target sequence from the } \\
\text { gene ZMO0875 }\end{array}$ & This study \\
\hline
\end{tabular}

Table S3. The nucleotide sequence of primers used in this work ${ }^{*}$.

\begin{tabular}{ll}
\hline Name & Sequence (5’-3') \\
\hline Zm4C1S3.F & CATAGACACCGGAAGGTGCG \\
Zm4C1S6.R & AGCGTATCGGCTATCAGGCAC \\
Zm4C2S2.F & GCTGTGAGCGTGACGATATGC \\
Zm4C2S5.R & GCGTCTGCAGATACGACTACC \\
ZmC1S1-3TGG.F1 & CCATAGCAGTGCCAGTGCTATCAAGAAAGAAATCCGTGGAGCTCCAATTCGCCC \\
ZmC1S1-3TGG.R1 & GGATTTCTTCTTGATAGCACTGGCACTGCTATGGCGATACCGTCGACCTCGAG \\
ZmC1S1-3GG.F2 & CCTAGCAGTGCCAGTGCTATCAAGAAAGAAATCCGTGGAGCTCCAATTCGCCC \\
ZmC1S1-3GG.R2 & GGATTTCTTTCTTGATAGCACTGGCACTGCTAGGCGATACCGTCGACCTCGAG \\
ZmC1S3-3AGG.F1 & CCTCCGTGCGTCATAGACACCGGAAGGTGCGCCGTGTGGAGCTCCAATTCGCCC \\
ZmC1S3-3AGG.R1 & ACGGCGCACCTTCCGGTGTCTATGACGCACGGAGGCGATACCGTCGACCTCGAG \\
ZmC1S3-3GG.F2 & CCCCGTGCGTCATAGACACCGGAAGGTGCGCCGTGTGGAGCTCCAATTCGCCC \\
ZmC1S3-3GG.R2 & ACGGCGCACCTTCCGGTGTCTATGACGCACGGGGCGATACCGTCGACCTCGAG \\
pBR_Cri01.F & AGCGGTACCTTATGGCCGAGTGAAGGTC \\
pBR_Cri01.R & AGTTAAGCTTGCAGGCTTTGTTACCCGC \\
pBRC1-0293S1.F & ATTATTACTAGTATTCTCTTATTGTTCACTGCCGCACAGGCAGCTTAGAAAAGA \\
pBRC1-0293S1.R & ATACTAGTAATAATTTCTTGTTGTTTCTAAGCTGCCTGTGCGGCAGTGAACTAG \\
pBRC1-0293S3.F & TGATGCTTCCCGAAAGTCCTCGCGTTCACTGCCGCACAGGCAGCTTAGAAATTC \\
pBRC1-0293S3.R & TTCGGGAAGCATCATCATTGAGCTTTCTAAGCTGCCTGTGCGGCAGTGAACAAA \\
pBRC1-0875S1.F & GAAGTCACTGTTTCAGTGCGCAGTTCACTGCCGCACAGGCAGCTTAGAAAAGA \\
pBRC1-0875S1.R & AAAACAGTGACTTCGCCGGGGGGTTTCTAAGCTGCCTGTGCGGCAGTGAACTAG \\
\hline
\end{tabular}

*The sequences underlined are identical to the spacer 1 and 3 of CRISPR locus P1 of Z. mobilis ZM4, respectively. The PAM sites are boxed. The shadow sequences with shadow match to the MCS region of pBBR1MCS2. 